\title{
Considerations for Incorporating Trauma-Informed Care Content within Special Education Teacher Preparation and Professional Development Programs
}

\author{
AUTHORS \\ William Hunter, Jonté C. Taylor, \\ Monica Bester, Sandra Nichols \\ and Carlomagno Panlilio
}

Journal of Special

Education Preparation

1(2), 48-55

(C) 2021 Hunter, Taylor, Bester, Nichols and Panlilio

Licensed with CC-BY-NC-ND 4.0

License

DOI: 10.33043/JOSEP.1.2.48-55

openjournals.bsu.edu/JOSEP

\section{ABSTRACT}

Trauma-informed care (TIC) is the practice of consciousness and awareness of trauma that guides educators in developing academic and behavioral support for students with exceptionalities who have experienced trauma. TIC can support students from the lens of Positive Behavioral Intervention Supports (PBIS) and Social Emotional Learning (SEL) within Multi-Tiered Systems of Support (MTSS). The purpose of this article is to explore the integration of TIC practices within classrooms that utilize the MTSS framework and to assist pre-service and in-service teachers with implementing TIC practices within inclusive and restrictive K-12 learning environments.

\section{KEYWORDS}

\section{Multi-tiered systems of support, school-wide positive} behavior supports and interventions, social and emotional learning, trauma-informed care

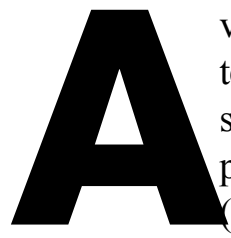

vast number of competencies are addressed in special education teacher preparation programs Council for Exceptional Children, 2015). Infusing teacher preparation programs with culturally responsive practices (Robertson et al., 2017) provides a forum for educators to address developmental, social, and cultural needs of pupils with and without exceptionalities in their future K-12 classrooms (Ladson-Billings, 2014). Principles of diversity, equity, and inclusion (DEI) are interwoven throughout all the knowledge and skills areas. Yet, a topic that does not always appear in focused research and practice within the field of special education and directly connects with DEI is trauma-informed care (TIC). TIC represents a holistic approach to structuring culture, practices, and policies to be sensitive to the experiences and needs of individuals who have experienced trauma (McInerney \& McKlindon, 2014). As it relates to education, over two-thirds of children residing in the United States have reported experiencing at least one traumatic event during their life (Stevens, 2017). Examples of trauma experienced by the $\mathrm{K}-12$ population that may impact behavior and academic performance include the loss of a parent, neglect, abuse, social violence, social isolation and natural disasters (Stevens, 2012). Furthermore, adverse childhood experiences (ACEs; Felitti et al., 1998) such as abuse, neglect, and household dysfunction are all common experiences for students with emotional/behavioral disorders (Cavanaugh, 2016). Data around childhood and school-age trauma make it imperative for teachers to consider the impact of trauma on students' behavioral and social development.

Students who have experienced trauma have unique needs, which must be addressed to adequately include them in educational settings. Trauma affects all aspects of students' lives. Their responses, ideations, behaviors, and more are inseparable from the negative impacts of trauma. Therefore, it is reasonable to estimate that providing teachers and teacher candidates with specific knowledge and skills grounded in TIC could have a positive impact on student 
outcomes. When TIC is the basis of decision making, the emphasis changes from education to well-being, which more holistically encompasses students' DEI needs. Educators who practice TIC recognize and respond to the impact of childhood trauma and traumatic stress (National Child Traumatic Stress Network, 2018).

Although Multi-Tiered Systems of Support (MTSS) is a widely used framework for the process of providing interventions, TIC is an approach that emphasizes how the framework and interventions are implemented (Cavanaugh, 2016). MTSS encompasses Positive Behavior Intervention Supports (PBIS) which offer a range of interventions that are applied systematically, with fidelity, and provide behavioral supports of increasing intensity across delivery tiers. There is a need for school mental health practices, such as TIC, to be aligned with PBIS, especially when supporting students with exceptionalities, like those with emotional behavioral disorders (Weist et al., 2018). Thus, the purpose of this article is to explore the integration of TIC practices within MTSS frameworks and detail TIC practices that can be included within special education teacher preparation programs and professional development for in-service teachers working with students in inclusive/restrictive K-12 settings.

\section{Trauma and Behavioral Challenges in Special Education}

Historically, special educators have intentionally and unintentionally excluded environmental factors during disability identification and accommodation (Berardi \& Morton, 2017). Recently, researchers have suggested that experiencing maltreatment places students at a higher risk for developing disabilities, making TIC relevant for the field of special education specifically (Corr \& Santos, 2017; Panlilio \& Corr, 2020).
According to Merikangas et al. (2010), roughly one out of five students experience mental health challenges that lead to externalizing behaviors such as inattention, impulsivity, and general disruptive behavior. Childhood adversities and traumatic experiences, particularly complex trauma, have often been associated with toxic stress responses in children, defined as the prolonged activation of the stress response system in the absence of responsive caregiving (Shonkoff et al., 2009; Shonkoff et al., 2012). These toxic stress responses, in turn, lead to a host of negative outcomes for children that include physical, psychological, social, and behavioral problems (D'Andrea et al., 2012). Mueser and Taub (2008) reported that post-traumatic stress has been experienced by $30 \%$ of adolescents with emotional and behavioral disorders (EBD). Walker and colleagues (2004) also asserted that students with EBD commonly deal with ACEs and situations that negatively impact their social, emotional, and cognitive well-being. Additionally, in a large-scale study from the Centers for Disease Control and Prevention (CDC; Felitti et al., 1998), three categories of ACEs were recognized: abuse, neglect, and household dysfunction. When examining results from each category, Felitti et al. found that the most prevalent ACEs were $28.3 \%$ sexual abuse (abuse category), 14.8\% emotional neglect (neglect category), and $26.9 \%$ household substance abuse (household dysfunction category). These findings were further supported by more recent findings from Lightfoot and others (2011), indicating that children in the welfare system who have experienced maltreatment were commonly identified as having emotional disturbances. Although connections have been established between disability diagnoses and childhood trauma (Corr \& Santos, 2017; Panlilio \& Corr, 2020), research and scholarship that integrate TIC into special education teacher preparation programs are minimal.

To effectively meet the needs of students with exceptionalities, including students with EBD, one must be familiar with the students' social-emotional, physical, cognitive, and communication skills (Benner et al., 2013). The education of students with EBD is challenging, which is attributed to the complex nature of the disorder (Kauffman \& Landrum, 2018). Subsequently, understanding TIC could be an essential element in special education teacher preparation, as it promotes equitable practice (Herrenkohl et al., 2019). Furthermore, given the compulsory nature of K-12 education in the United States, educators are at an important nexus of providing academic rigor and instruction, as well as providing the necessary resources to protect and improve the well-being of their students (Oyler, 2011). While educators will ideally seek to protect children from complex traumatic experiences, a need also exists to help them move from the role of protectors toward the role of promoters of their students' behavioral well-being. In order to do this, schools need to adopt a school-wide trauma-informed approach to engaging with students.

Efforts to support students who experience trauma or maltreatment should occur as a natural part of the educational experience. Consequently, teachers need to be prepared to address the needs of all students who enter their classrooms. As such, preparing teachers for this reality is of utmost importance. Although TIC and the nuances within it could be taught as a standalone course at the pre-service teacher level, classroom and behavior management courses are more than appropriate settings to broach the subject of TIC and introduce the topic to future special educators who will be working with students who experience behavioral challenges. 


\section{Trauma-Informed Care and Multi-Tiered Systems of Support in Behavior}

A TIC approach has been broadly defined as a prevention approach by any child- or family-serving system that recognizes and responds to the impact of trauma and traumatic stress on children, as well as anyone else that is part of that system, such as caregivers or staff (National Child Traumatic Stress Network, 2018). Specifically, school-based TIC approaches apply a philosophy toward a school system wherein early adversity and trauma are recognized as important factors that are associated with students' academic-related competencies (Panlilio, 2019). Chafouleas and colleagues (2016) recommended that such schoolbased trauma-informed approaches be framed within a multi-tiered framework of school-based service delivery. MTSS is typically conceptualized as prevention-oriented models that have traditionally been used to deliver targeted services for students to support their school-based needs.

MTSS is a comprehensive framework that provides support for students through targeted preventions and interventions that are connected to providing support for students by catering to their whole self (Hunter et al., 2015). These supports are intentional and developed through a process of identifying a student's level of behavioral needs (Sailor et al., 2021). Multi-tiered models typically include a three-tiered pyramid approach, following the CDC prevention models (Centers for Disease Control and Prevention, 2021), wherein Tier 1 includes low intensity support, and Tiers 2 and 3 include moderate and high intensity support guided by the data-based assessments at each tier. MTSS frameworks that focus on behavior are usually described as School-Wide Positive Behavior Interventions and Supports (SWPBIS), and they focus on the process of students learning how to apply the needed social and emotional skills necessary to control their emotional impulses, set goals, and interact with others competently (i.e., social, and emotional learning [SEL; Kendziora \& Yoder, 2016]).

Presently, school systems are implementing SWPBIS through MTSS for students with and without exceptionalities in the school (Steed \& Shapland, 2020). MTSS has been an influential framework for teachers and school administrators due to opportunities provided by the framework to: (a) create individualized plans of academic and behavioral support within the classroom, (b) reduce the number of distractions and triggers in the least restrictive classroom setting, and (c) implement intentional instruction with awareness of trauma triggers in the classroom (Benner et al., 2013). The Schools Committee of the National Child Traumatic Stress Network (2018) suggests using an MTSS model to incorporate TIC into schools to widen the scope of intentional instruction. This would suggest that TIC can be interwoven with emotional and behavioral supports to improve cross-cutting student outcomes.

In applying TIC within MTSS systems, it is critical to remember the foundational needs of students schoolwide. Cavanaugh (2016) described six trauma-informed school practices; however, we posit that these practices are better described as considerations for setting a supportive school climate by implementing TIC with the MTSS frameworks of SWPBIS and SEL. In the training of pre-service/in-service teachers, particularly when it comes to behavior and motivation, understanding the "why" is essential in supporting students with traumatic experiences. Cavanaugh's six trauma-informed school considerations help frame the conversation around reasons teachers (and schools' writ large) need to be cognizant of trauma as they implement PBIS and SEL systems. School climate should include consideration for:

1. Safety and consistency knowing that students who experience trauma have usually experienced life circumstances that have threatened their physical and emotional safety as well as lives full of unpredictability.

2. Culturally responsive practices as students' life circumstances vary by culture, background, and language and can provide insight on trauma that they may have experienced.

3. Positive interactions that include positive praise statements, behavior specific praise, and tangible reward systems that support fostering a climate that is encouraging to students.

4. Peer supports that encourage positive interactions with others that have similar experiences or come from similar backgrounds and allow students to see, hear, and practice opportunities that allow for social, emotional, and confidence growth.

5. Targeted supports that will scaffold behavior within tiered systems including PBIS and SEL.

6. Individualized supports that may include identification of students with the most intensive traumatic experiences for services in and out of the school setting.

In addition, SWPBIS and SEL can play an important role within an MTSS framework. The trauma-informed teacher, after collecting data from the student using universal methods, may assign the student to work with a specific group or partner as a tier two intervention (Fondren et al., 2020). If the tier two intervention does not yield the desired results, the student will receive 1:1 support in the least restrictive setting before referral to an interventionist for personalized support in needed areas (Meyer et al., 2013). 


\section{Trauma-Informed Care and School-Wide Positive Behavior Interventions and Supports}

The focus of SWPBIS is prevention of student behavioral problems through a range of interventions applied systematically and with fidelity across the three MTSS service delivery tiers: (a) Tier 1 (primary) serves the entire classroom and includes pre-diagnosis interventions, (b) Tier 2 (secondary) involves targeted support in small groups, and (c) Tier 3 (tertiary) integrates individualized support (Hunter et al., 2015). This framework is designed to improve academic and behavioral outcomes for students, providing teachers with access to and training in evidence-based practices (Hunter, 2020) and progress monitoring systems. One example includes self-monitoring, in which students working within Tier 2 (small group) engage in instructional learning and independence through self-regulation of behavioral goals that are embedded within their Behavioral Intervention Plan (BIP). TIC within a SWPBIS framework can be used proactively and reactively for students in need of behavioral support in the classroom. Another example is students receiving wraparound services (within tier 3) to allow for positive academic and behavioral outcomes in the classroom (Hunter et al., 2018). By integrating TIC into SWPBIS, educators can approach student behavior from a place of healing and understanding, which may positively affect student outcomes. The SWPBIS offers the opportunity for teachers to provide explicit and culturally responsive expectations, as well as to build mutually respectful relationships that establish an environment of positive student engagement. Through the MTSS framework, school systems will be able to integrate a holistic process that transforms classroom learning environments (Lane et al., 2014). As K-12 school leadership teams adopt social-emotion-

TABLE 1: Trauma Informed-Care within School-Wide Positive Behavior Interventions and Supports

\begin{tabular}{|c|c|}
\hline Tier & Checklist \\
\hline Tier 3 & $\begin{array}{l}\text { - Individual behavioral plans to support students academically, including } \\
\text { students transitioning from a restrictive environment into a least restrictive } \\
\text { environment. } \\
\text { - Wraparound Services featuring teacher, parent, mental health professional, } \\
\text { and social worker that focuses on planning, development, and monitoring } \\
\text { to allow for student success in the classroom from a positive behavioral } \\
\text { intervention support perspective. } \\
\text { - Wraparound Team ensuring that an intervention in the form of Trauma- } \\
\text { Focused Cognitive Behavioral Therapy (TFCBT) takes place. TFCBT is } \\
\text { an evidence-based strategy shown to be effective for students who have } \\
\text { experienced single, multiple, and/or complex traumatic events. }\end{array}$ \\
\hline Tier 2 & $\begin{array}{l}\text { - Intentional, small flexible grouping in which the instructor is providing an } \\
\text { opportunity for students to monitor their behavioral goals through Check-In/ } \\
\text { Check-Out. } \\
\text { - Intentional, small flexible grouping in which the instructor is providing an } \\
\text { opportunity for students to engage in conflict management. } \\
\text { - Providing support for instructional learning and independence through } \\
\text { self-regulation and self-monitoring of behavioral goals that are embedded } \\
\text { within the student's Behavioral Intervention Plan (BIP). }\end{array}$ \\
\hline Tier 1 & $\begin{array}{l}\text { - Teachers providing explicit, culturally responsive expectations and building } \\
\text { mutually respectful relationships to set a positive, engaging learning environ- } \\
\text { ment. } \\
\text { - Peer-Mediated Instruction in which students have an alternative to large } \\
\text { group instruction by working with peers on academic task and problem-based } \\
\text { learning projects. } \\
\text { - Conscious teaching and awareness with adults modeling emotion regulation } \\
\text { and providing students with constructive, positive behavior to guide students. }\end{array}$ \\
\hline
\end{tabular}

al competency programs to target the needs of their students with and without exceptionalities, a PBIS framework can provide the necessary structures to teach social-emotional competencies effectively, including the use of teams to examine data, monitor fidelity, and measure the overall effectiveness (Barret et al., 2018). Furthermore, the implementation of MTSS and the integration of SWPBIS constitute a warranted shift in focus to the social and emotional needs of students (Panlilio, 2019). See Table 1 for a checklist of TIC practices that can be used within an SWPBIS framework for students.

\section{Trauma-Informed Care and Social and Emotional Learning}

SEL focuses on student understanding of the management of emotions, thoughts, and dispositions within five domains: (a) self-awareness, (b) self-management, (c) social awareness, (d) relationship skills, and (e) responsible decision-making (Collaborative for Academic, Social, and Emotional Learning, 2013). SEL's emphasis on 


\section{TABLE 2:}

\section{Trauma Informed-Care Practices within Social and Emotional Learning}

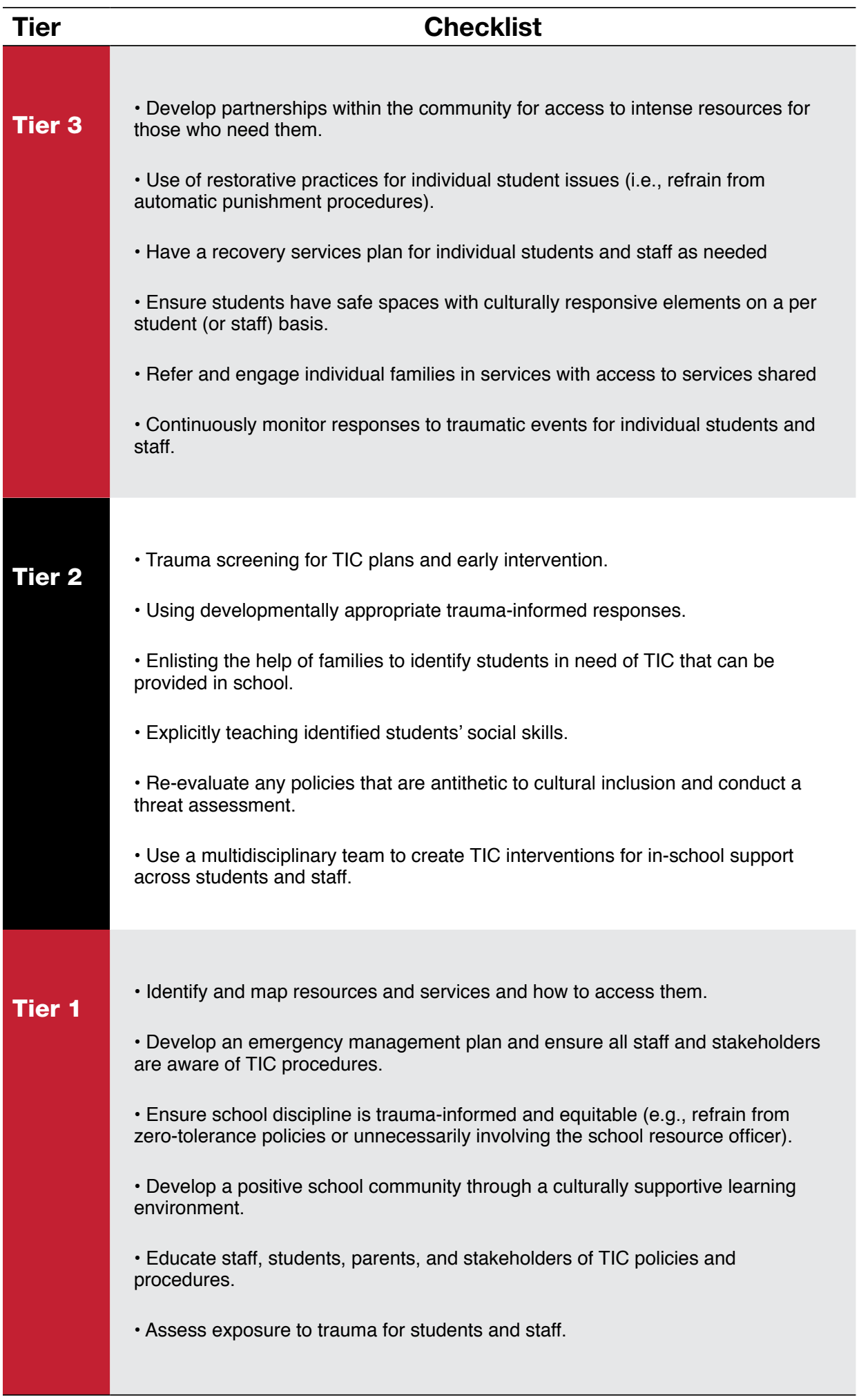

building positive relationships with others aligns with TIC's keen focus on relationships that provide support for students; thus, the two are easily implemented in tandem. One example within Tier 1 includes school consideration of identifying and mapping resource services, and how students can access them. TIC emphasizes the notion of providing school-age children safe spaces and environments (Putman et al., 2020) while SEL helps school-age children survive and cope in various situations (affected by trauma). Another example within Tier 1 includes the administration team/teachers developing an emergency plan and ensuring all staff and stakeholders are aware of TIC procedures. By having a focus on SEL and TIC when working with students, educators are not only knowledgeable about the potential effects but actions as well. See Table 2 for a checklist of TIC practices that can be used within an SEL framework for students.

\section{Incorporating TIC within Special Education Teacher Preparation and Professional Development Programs}

TIC training can be infused within courses within special education teacher preparation programs. One option for consideration is ungraduated/graduate classroom/behavioral management courses. This can be done through connecting the content of TIC within the Council for Exceptional Children (CEC) High Leverage Practices (HLP's). HLP's for teachers are a set of clearly defined instructional practices that are observable, used frequently by teachers, and associated with improved student outcomes across grade levels, content areas, and academic skills within MTSS (McLeskey et al., 2017). The four domains for HLP's include (a) Collaboration, (b) Assessment, (c) Social Emotional Practices, and (d) 
Instruction. From the Collaboration Domain, specifically, HLP \#1 Collaborate with Professionals to Increase Student Success, classroom/behavioral management instructors can provide detail on what wraparound services are. Wraparound Services (provided within Tier 3 of PBIS) can feature educational teams that includes a student's teacher, parent, mental health professional, and social worker in which the team focuses on planning, development, and monitoring to allow for student success in the classroom from a PBIS perspective (Shepherd \& Linn, 2015). From the Assessment Domain, HLP \#4 Use Multiple Sources of Information to Develop a Comprehensive Understanding of a Student's Strengths and Needs, a discussion on Behavioral Support Plans for students, including student transition within least restrictive environments, can be a featured topic within a classroom/behavioral management course. From the Social Emotional Domain, specifically, HLP \#9 Teach Social Behaviors (within the domain of Social Emotional Practices) connects with TIC practices, particularly Tier $2 /$ SEL in which educators explicitly teach identified students' social skills. Instructors can create lessons/discussion points on the aspects of teachers providing social skill instruction. Social skills training programs are often overlooked components of behavior and classroom management plans; however, social skills training is an intervention that may increase the social skills and social competencies of students with EBD (Shepherd \& Linn, 2015). From the Instruction Domain, specifically HLP \#17, Use Flexible Grouping, instructors can model what flexible grouping is. Flexible Grouping incorporates cooperative learning principles where teachers assign students to heterogeneous groups (different content skill mastery, gender, and cultural/ethnic identities) based on

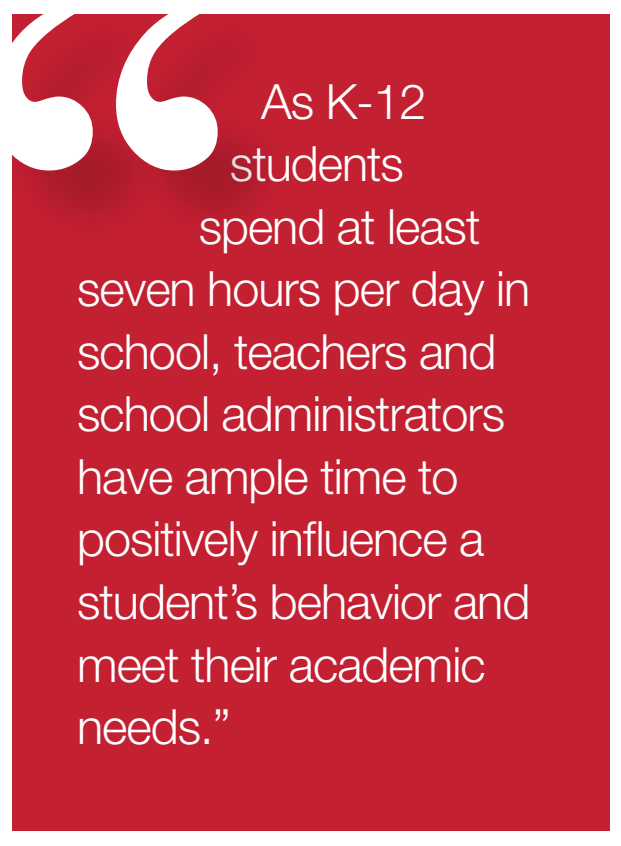

clear learning goals, providing a forum for peer mediation, and the opportunity for positive and corrective feedback to support student of learning (Hunter, 2020). Table 1 and 2 feature content on TIC and various connections to HLP's. It is recommended for pre-service/ in-service teachers to engage with content that connects TIC and HLP's within MTSS (Taylor \& Bhana, 2021.)

Considerations for special education professional development includes teachers undergoing an extensive training that addresses the following components:

- Understanding Trauma and ACEs (Dong et al., 2003)

- Challenging current thought processes vs. TIC attributions (Hoskins et al., 2018)

- Identifying ways educators may be trauma informed (Plumb et al., 2016)

- Direct overview of MTSS (August et al., 2018)

National Centers and state agencies provide continuous professional development to support in-service teachers with implementing strategies associated with the MTSS framework (Barret et al., 2018). School-wide training in the implementation of TIC practices, with specific training at the classroom level, is recommended, and educators are encouraged to bear in mind that the process of becoming a trauma-informed institution requires continuous evaluation. As an ongoing learning process, school systems should incorporate observation of trauma-informed practices during teacher evaluation, as well as provide ongoing professional development opportunities that continuously support teachers within schools that utilize the MTSS framework.

\section{Final Thoughts}

As K-12 students spend at least seven hours per day in school, teachers and school administrators have ample time to positively influence a student's behavior and meet their academic needs. At this point, teacher education around TIC is not a national requirement, as there is currently no mandated trauma-informed training for educators. However, educators will not be able to implement trauma-informed practices without first being introduced to TIC (Plumb et al., 2016), practices that are crucial to working with vulnerable student populations.

The goal of joining principles of TIC with the MTSS framework, and interventions (e.g., SWPBIS and SEL) is to make sure consideration is given to the behavioral and emotional aspects surrounding current interventions and practices that are effective with all students (Adams, 2014). The overall goal is to design actionable steps toward creating mandatory TIC trainings, certifications, and educational curricula for educators and educational leaders within special education teacher preparation programs and the continuation of professional development (Cavanaugh, 2016). In her work, Ladson-Billings (1999) shared the importance of preparing educators for teaching diverse populations with indi- 


\section{ABOUT THE AUTHORS}

\section{William Hunter}

William Hunter is an associate professor of special education at the University of Memphis. Dr. Hunter's background includes working as a special education teacher in urban schools located within the Greater Cincinnati area for 12 years and as a special education administrator for 2 years. He has authored and co-authored publications and presentations in the topics of active engagement, classroom management, culturally relevant pedagogy, transition, and instructional support for students with exceptionalities.

\section{Jonté C. Taylor}

Jonte' C. Taylor (JT), Ph.D. is an Associate Professor of Special Education at Pennsylvania State University (Penn State). His research includes examining effective strategies for inclusive STEAM education for students with disabilities and improving school/class-room climates for students, families, and teachers. His scholarship includes determining effective support for students with disabilities in STEAM instruction, the notion of educational followership and leadership, effective classroom and behavioral motivation, and diversity consideration in educational placements.

\section{Monica Bester}

Monica Bester is an Educator, Doctoral Candidate, and Author of the book They Never Told, which focuses on the development of trauma-informed relationships with children. $\mathrm{Her}$ research includes trauma-informed care, special education, and working with students diagnosed with an emotional disorder. Her work as a social worker in the mental health field catapulted her interest in trauma research and education. Monica makes it a priority to not only implement healthy boundaries, self-care rituals, and preventative mental health measures for herself but to help others find and keep their balance as well when working in high stress environments with individuals impacted by trauma.

\section{- Sandra Nichols}

Sandra Nichols is a professor of special education at the University of Memphis. Dr. Nichols background includes more than 20 years of service in the field of special education as a behavior interventionist, early interventionist, administrator, and teacher educator in rural and urban schools. She has authored and co-authored publications and presentations on the topics of partnership development, rural education, culturally relevant pedagogy, critical race theory, and instructional support for students with exceptionalities.

\section{Carlomagno Panlilio}

Carlomagno Panlilio is an Assistant Professor of educational psychology, and a faculty member with the Child Maltreatment Solutions Network, at the Pennsylvania State University. His program of research focuses on the dynamic interplay between development and learning for children who experience early adversity, and how elucidation of such processes can inform traumainformed classroom instruction and prevention efforts. Dr. Panlilio previously worked as a family therapist in community agencies serving child welfare-involved families, including those in foster care. vidualized needs. University teacher education programs that include classroom behavior management courses should include instruction and support for TIC in MTSS frameworks (e.g., SWPBIS and SEL) which will assist with supporting students from diverse populations with individualized needs. By changing the mindsets and approaches of educators, student learning outcomes can be positively affected (Wiest-Stevenson \& Lee, 2016).

Pre-service special education teachers who are trained to recognize the signs of trauma and to implement instructional strategies and interventions which support students who have been exposed to trauma can better provide equitable services to students with exceptionalities (McInerney \& McKlindon, 2014). As TIC is implemented, the educational nexus would not be replaced. Rather, special education research and practice would be complemented with TIC research and practice to provide a more holistic approach to student success.

\section{References}

Adams, J. M. (2014). New 'trauma-informed' approach to behavioral disorders in special education. https://edsource.org/2014/ new-trauma-informed-approach-to-behavioral-disorders-in-special-education/56753

August, G. J., Piehler, T. F., \& Miller, F. G. (2018). Getting "SMART" about implementing multi-tiered systems of support to promote school mental health. Journal of School Psychology, 66(1), 85-96. https://doi.org/10.1016/j.jsp.2017.10.001

Benner, G. J., Kutash, K., Nelson, J. R., \& Fisher, M. B. (2013). Closing the achievement gap of youth with emotional and behavioral disorders through multitiered systems of support. Education and Treatment of Children, 36(3), 15-29. https://doi.org/10.1353/etc.2013.0018

Berardi, A., \& Morton, B. M. (2017). Maximizing Academic Success for Foster Care Students: A Trauma-Informed Approach. Journal of At-Risk Issues, 20(1), 10-16.

Cavanaugh, B. (2016). Trauma-informed classrooms and schools. Beyond Behavior, 25(2), 41-46. https://doi. org/10.1177/107429561602500206

Chafouleas, S. M., Johnson, A. H., Overstreet, S., \& Santos, N. M. (2016). Toward a blueprint for trauma-informed service delivery in schools. School Mental Health, 8(2), 144-162. https://doi.org/10.1007/ s12310-015-9166-8

Centers for Disease Control and Prevention. (2021, January 28). The social-ecological model: A framework for prevention. https://www.cdc.gov/violenceprevention/ about/social-ecologicalmodel.html

Corr, C., \& Santos, R. M. (2017). Abuse and young children with disabilities: A review of the literature. Journal of Early Intervention, 39(1), 3-17. https://doi. org/10.1177/1053815116677823

Council for Exceptional Children. (2015). What Every Special Educator Must Know: Professional Ethics and Standards. Arlington, VA: CEC.

D'Andrea, W., Ford, J., Stolbach, B., Spinazzola, J., \& van der Kolk, B. A. (2012). Understanding interpersonal trauma in children: Why we need a developmentally appropriate trauma diagnosis. American Journal of Orthopsychiatry, 82(2), 187-200. https://doi.org/10.1111/j.19390025.2012.01154.X

Dong, M., Anda, R. F., Dube, S. R., Giles, W. H., \& Felitti, V. J. (2003). The relationship of exposure to childhood sexual abuse to other forms of abuse, neglect, and household dysfunction during childhood. Child Abuse \& Neglect, 27(6), 625-639. https://doi.org/10.1016/S01452134(03)00105-4

Felitti, V. J., Anda, R. F., Nordenberg, D., Williamson, D. F., Spitz, A. M., Edwards, V., \& Marks, J. S. (1998). Relationship of childhood abuse and household dysfunction to many of the leading causes of death in adults: The Adverse Childhood Experiences (ACE) Study. American Journal of Preventive Medicine, 14(4), 245-258. https://doi.org/10.1016/S07493797(98)00017-8

Fondren, K., Lawson, M., Speidel, R., McDonnell, C. G., \& Valentino, K. (2020). Buffering the effects of childhood trauma within the school setting: A systematic review of trauma-informed and trauma-responsive interventions among trauma-affected youth. Children and Youth Services Review, 109. https://doi.org/10.1016/j. childyouth.2019.104691

Collaborative for Academic, Social, and Emotional Learning. (2013). https://casel.org/ wp-content/uploads/2016/01/2013-casel-guide-1.pdf

Herrenkohl, T. I., Hong, S., \& Verbrugge, B. (2019). Trauma-informed programs based in schools: Linking concepts to practices and assessing the evidence. American Journal of Community Psychology, 64(3-4), 373-388. https://doi.org/10.1002/ 
ajcp. 12362

Hoskins, D., Duncan, L. G., Moskowitz, J. T., \& Ordóñez, A. E. (2018). Positive adaptations for trauma and healing (PATH), a pilot study of group therapy with Latino youth. Psychological Trauma: Theory, Research, Practice, and Policy, 10(2), 163-172. https://doi.org/10.1037/tra0000285

Hunter, W. (2020). Flexible grouping for students with emotional and behavioral disorders. Behavior Today Newsletter, 36(4), 16-20.

Hunter, W., Elswick, S., \& Casey, L. (2018). Efficient wraparound service model for Students with emotional and behavioral disorders: A collaborative model school social workers and teachers. Children and Schools, 40(1), 59-61. https://doi. org/10.1093/cs/cdx030

Hunter, W., Maheady, L., Jasper, A., Williamson, R. L., Murley, R., \& Stratton, E. (2015). Numbered heads together as a tier 1 instructional strategy in multi-tiered systems of support. Education and Treatment of Children, 38(3), 345-362. https://www.jstor. org/stable/44684070

Kauffman, J. M., \& Landrum, T. J. (2018). Characteristics of emotional and behavioral disorders of children and youth with disabilities (11th ed.). Pearson.

Kendziora, K., \& Yoder, N. (2016). When districts support and integrate social and emotional learning (SEL). Education Policy Center. https://files.eric.ed.gov/fulltext/ ED571840.pdf

Ladson-Billings, G. (1999) Preparing teachers for diverse student populations: a critical race theory perspective (pp. 221-247). In A. Iran-Nejad \& P. Pearson (Eds) Review of research in education. American Educational Research Association.

Ladson-Billings, G. (2014). Culturally relevant pedagogy 2.0: Aka the remix. Harvard

Educational Review, 84(1), 74-84. https://doi. org/10.17763/haer.84.1.p2rj131485484751

Lane, K. L., Oakes, W. P., \& Menzies, H. M. (2014). Comprehensive, integrated, threetiered models of prevention: Why does my school—and district — need an integrated approach to meet students' academic, behavioral, and social needs? Preventing School Failure, 58(3), 121-128. https://doi. org/10.1080/1045988X.2014.893977

Lightfoot, E., Hill, K., \& LaLiberte, T. (2011). Prevalence of children with disabilities in the child welfare system and out of home placement: An examination of administrative records. Children and Youth Services Review, 33(11), 2069-2075. https://doi org/10.1016/i.childyouth.2011.02.019

McInerney, M., \& McKlindon, A. (2014). Unlocking the door to learning: Trauma-informed classrooms \& transformational schools. Education Law Center. http://www. elc-pa.org/wp-content/uploads/2015/06/ Trauma-Informed-in-Schools-Class-
rooms-FINALDecember2014-2.pdf

McLeskey, J., Barringer, M. D., Billingsley, B., Brownell, M., Jackson, D., Kennedy, M., Lewis, T., Maheady, L., Rodriguez, J., Scheeler, M. C., Winn, J., \& Ziegler, D. (2017). High-leverage practices in special education. Council for Exceptional Children \& CEEDAR Center.

Merikangas, K. R., He, J. P., Burstein, M., Swanson, S. A., Avenevoli, S., Cui, L., ... \& Swendsen, J. (2010). Lifetime prevalence of mental disorders in US adolescents: results from the National Comorbidity Survey Replication-Adolescent Supplement (NCS-A). Journal of the American Academy of Child \& Adolescent Psychiatry, 49(10), 980-989. https://doi.org/10.1016/j. jaac.2010.05.017

Meyer, L. D., Anderson, J. A., \& McQueen, K. (2013). Cultural competence, systems of care, and students with emotional and behavioral challenges. Education, 133(3), 319-329.

Mueser, K. T., \& Taub, J. (2008). Trauma and PTSD among adolescents with severe emotional disorders involved in multiple service systems. Psychiatric Services, 59(6), 627634. https://ps.psychiatryonline.org/doi/ full/10.1176/ps.2008.59.6.627

National Child Traumatic Stress Network. (2018, October 3). Creating, supporting, and sustaining trauma-informed schools: A system framework. https://www.nctsn. org/resources/creating-supporting-and-sustaining-trauma-informed-schools-system-framework.

Oyler, C. (2011). Teacher preparation for inclusive and critical (special) education. Teacher Education and Special Education, 34(3), 201-218. https://doi. org/10.1177\%2F0888406411406745

Panlilio, C. C. (2019). Trauma-informed schools: Integrating child maltreatment prevention, detection, and intervention. Springer.

Panlilio, C. C., \& Corr, C. (2020). Child maltreatment: Pathways to educational achievement through self-regulation and self-regulated learning. In A. J. Martin, R. A. Sperling, \& K. J. Newton (Eds.), Handbook of educational psychology and students with special needs. Routledge.

Plumb, J. L., Bush, K. A., Kersevich, S. E. (2016). Trauma-sensitive schools: An evidence-based approach. School Social Work Journal, 40(2), 37-60.

Robertson, P. M., McFarland, L. A., Sciuchetti, M. B., \& García, S. B. (2017). Connecting the dots: An exploration of how pre-service special education teachers make sense of disability and diversity. Teaching and Teacher Education, 65, 34-47. https://doi. org/10.1016/j.tate.2017.02.020

Sailor, W., Skrtic, T., Cohn, M., \& Olmstead, C. (2021). Preparing teacher educators for statewide scale-up of multi-tiered system of support (MTSS). Teacher Education and Special Education, 44(1) 24-41. https://doi. org/10.1177\%2F0888406420938035

Shepherd, T. L., \& Linn, D. (2015). Behavior and classroom management in the multicultural classroom: Proactive, active, and reactive strategies. Sage Publications.

Shonkoff, J. P., Boyce, W. T., McEwen, B. S. (2009). Neuroscience, molecular biology, and the childhood roots of health disparities: Building a new framework for health promotion and disease prevention. $J A M A, 301(21), 2252-2259$. https://doi. org/10.1001/jama.2009.754

Shonkoff, J. P., Garner, A. S., Siegel, B. S., Dobbins, M. I., Earls, M. F., McGuinn, L., ... \& Committee on Early Childhood, Adoption, and Dependent Care. (2012). The lifelong effects of early childhood adversity and toxic stress. Pediatrics, 129(1), 232-246. https://doi.org/10.1542/peds.2011-2663

Steed, E. A., \& Shapland, D. (2020). Adapting social emotional multi-tiered systems of supports for kindergarten classrooms. Early Childhood Education Journal, 48(2), 135-146. https://doi.org/10.1007/s10643019-00996-8

Stevens, J. E. (2012, February 28). Spokane, WA, students' trauma prompts search for solutions. ACES Too High. https:// acestoohigh.com/2012/02/28/spokane-wastudents-child-trauma-prompts-search-forprevention/

Stevens, J. E. (2017, December 6). The adverse childhood experiences study-The largest public health study you never heard of. The Huffington Post. http://www.huffingtonpost. com/janeellen-stevens/the-adverse-childhood-exp 1 b 1943647.html

Taylor, J., \& Bhana, N. (2021). Incorporating high-leverage practice 7 in classroom/ behavior management courses. Journal of Special Education Preparation, 1(1), 47-54 https://doi.org/10.33043/JOSEP.1.1.47-54

United States, Department of Education, Office of Special Education and Rehabilitative Services. (2020). 41st Annual Report to Congress on the Implementation of the Individuals with Disabilities Education Act.

Walker, H. M., Ramsey, E., \& Gresham, F. M. (2004). Antisocial behavior in schools: Evidence-based practices (2nd ed.). Wadsworth.

Wiest-Stevenson, C., \& Lee, C (2016). Trauma-informed schools. Journal of Evidence-Informed Social Work, 13(5), 498-503. https://doi.org/10.1080/23761407. 2016.1166855

Weist, M. D., Eber, L., Horner, R., Splett, J., Putnam, R., Barrett, S., ... \& Hoover, S. (2018). Improving multitiered systems of support for students with "internalizing" emotional/behavioral problems. Journal of Positive Behavior Interventions, 20(3), 172-184. https://doi. org $/ 10.1177 \% 2 \mathrm{~F} 1098300717753832$ 